Article

\title{
Individual Tree Detection and Qualitative Inventory of a Eucalyptus sp. Stand Using UAV Photogrammetry Data
}

\author{
André Almeida $\left.{ }^{1 *} \mathbb{(}\right)$, Fabio Gonçalves ${ }^{2}{ }^{(0)}$, Gilson Silva ${ }^{3}$, Adriano Mendonça ${ }^{3}{ }^{(D}$, Maria Gonzaga ${ }^{4}$, Jeferson Silva ${ }^{5}$, \\ Rodolfo Souza $\left.{ }^{6}{ }^{(}\right)$, Igor Leite ${ }^{1}{ }^{\mathbb{D}}$, Karina Neves ${ }^{7}$, Marcus Boeno ${ }^{2}$ and Braulio Sousa ${ }^{8}$
}

1 Department of Agricultural Engineering, Federal University of Sergipe, Av. Marechal Rondon, s/n, São Cristóvão 49100-000, Brazil; igorleite@academico.ufs.br

2 Canopy Remote Sensing Solutions, Florianópolis 88032-005, Brazil; fabio@canopyrss.tech (F.G.); marcus@canopyrss.tech (M.B.)

3 Department of Forest and Wood Sciences, Federal University of Espírito Santo, Jerônimo Monteiro 29550, Brazil; gilson.silva@pq.cnpq.br (G.S.); adriano.mendonca@ufes.br (A.M.)

4 Department of Agronomic Engineering, Federal University of Sergipe, Av. Marechal Rondon, s/n, São Cristóvão 49100-000, Brazil; isidoria@academico.ufs.br

5 Forest Sciences Post Graduation Program, Federal University of Espírito Santo, Jerônimo Monteiro 29550, Brazil; jeferson.m.silva@edu.ufes.br

6 Department of Biological and Agricultural Engineering, Texas A\&M University, College Station, TX 77840, USA; rodolfo.souza@tamu.edu

7 Water Resources Post Graduation Program, Federal University of Sergipe, Av. Marechal Rondon, s/n, São Cristóvão 49100-000, Brazil; karinaneves@academico.ufs.br

8 Department of Zootechnics, Federal University of Sergipe, Av. Marechal Rondon, s/n, São Cristóvão 49100-000, Brazil; brauliosousa@academico.ufs.br

check for updates

Citation: Almeida, A.; Gonçalves, F.; Silva, G.; Mendonça, A.; Gonzaga, M.; Silva, J.; Souza, R.; Leite, I.; Neves, K.; Boeno, M.; et al. Individual Tree Detection and Qualitative Inventory of a Eucalyptus sp. Stand Using UAV Photogrammetry Data. Remote Sens. 2021, 13, 3655. https://doi.org/ $10.3390 /$ rs13183655

Academic Editor: Lin Cao

Received: 30 June 2021

Accepted: 6 September 2021

Published: 13 September 2021

Publisher's Note: MDPI stays neutral with regard to jurisdictional claims in published maps and institutional affiliations.

Copyright: (c) 2021 by the authors. Licensee MDPI, Basel, Switzerland. This article is an open access article distributed under the terms and conditions of the Creative Commons Attribution (CC BY) license (https:// creativecommons.org/licenses/by/ $4.0 /)$.
* Correspondence: andre.almeida@ufs.br

Abstract: Digital aerial photogrammetry (DAP) data acquired by unmanned aerial vehicles (UAV) have been increasingly used for forest inventory and monitoring. In this study, we evaluated the potential of UAV photogrammetry data to detect individual trees, estimate their heights $(h t)$, and monitor the initial silvicultural quality of a 1.5-year-old Eucalyptus sp. stand in northeastern Brazil. DAP estimates were compared with accurate tree locations obtained with real time kinematic (RTK) positioning and direct height measurements obtained in the field. In addition, we assessed the quality of a DAP-UAV digital terrain model (DTM) derived using an alternative ground classification approach and investigated its performance in the retrieval of individual tree attributes. The DTM built for the stand presented an RMSE of 0.099 m relative to the RTK measurements, showing no bias. The normalized 3D point cloud enabled the identification of over $95 \%$ of the stand trees and the estimation of their heights with an RMSE of $0.36 \mathrm{~m}(11 \%)$. However, $h t$ was systematically underestimated, with a bias of $0.22 \mathrm{~m}(6.7 \%)$. A linear regression model, was fitted to estimate tree height from a maximum height metric derived from the point cloud reduced the RMSE by $20 \%$. An assessment of uniformity indices calculated from both field and DAP heights showed no statistical difference. The results suggest that products derived from DAP-UAV may be used to generate accurate DTMs in young Eucalyptus sp. stands, detect individual trees, estimate $h t$, and determine stand uniformity with the same level of accuracy obtained in traditional forest inventories.

Keywords: UAS; 3D point cloud; enhanced forest inventories; precision silviculture; SfM; individual tree detection; Gini; lorenz curve

\section{Introduction}

Brazil has one of the world's largest areas ( 9 million ha) of rapid-growth forest plantations. Of these, around $77 \%$ are Eucalyptus stands. The derived forest products supply domestic and foreign markets, with an estimated US\$ 11.3 billion of exports in 2019 [1]. Beyond its economic importance to the country, representing $1.2 \%$ of the national 
gross primary product (GPP), these plantations also play a key role in the promotion of ecosystem services such as carbon sequestration and reduction of the pressure on native forests.

The productivity of rapid-growth commercial stands, such as Eucalyptus, is defined by the environment, genetic material and silvicultural treatments applied during the production cycle [2]. Initial silvicultural quality has a direct impact on the productivity observed at the end of the growth cycle, highlighting the importance of its monitoring [3]. Silvicultural quality can be assessed by metrics that describe uniformity, such as the Gini index and the Lorenz curve [4-7]. Traditionally, these metrics are estimated from dendrometric characteristics of the trees (height, diameter at breast height, basal area, crown area, among others), measured during the initial growth of the stand [3]. Large planted areas with high growth rates subject to extreme climate change effects require even more attention in early-stage monitoring in order to maximize productivity at the end of the production cycle $[8,9]$.

In recent decades, remote sensing techniques provided an effective and reliable means of forest monitoring [10-14]. Three-dimensional (3D) remote sensing instruments such as light detection and ranging (LiDAR) stand out because of their precise measurements of vertical profiles of the forests, from which structural metrics are extracted and used to estimate the main dendrometric characteristics. Despite encouraging results in the characterization of forest plantations in Brazil [15-17], LiDAR data still incur high costs, hampering their operational use. As an alternative, digital aerial photogrammetry (DAP) data have been utilized by the scientific community in recent decades [18-21], as they have become more accessible with the popularization of unmanned aerial vehicles (UAV). Besides the lower costs, DAP-UAV products present similarities to LiDAR data and are generated at a higher point density in a shorter time interval $[22,23]$. Some studies indicate that the performance of UAV photogrammetry data is adequate for estimating the characteristics of Eucalyptus stands [24,25], thus making them a feasible alternative to forest monitoring [26,27].

Despite their potential and similarity to LiDAR data, some UAV photogrammetry products have limitations within vegetated areas, which may compromise their usage [28,29]. In digital terrain models (DTMs), for example, UAVs commonly overestimate elevation under the forest, leading to an underestimation of tree heights [30,31]. In contrast with LiDAR, DAP-UAV products cannot penetrate the forest canopy and describe the vertical profile of the vegetation in detail [23]. It is noteworthy that the capacity to penetrate the forest's vertical structure depends on the type of vegetation, age, canopy structure, disturbance history, and terrain characteristics [32,33].

In addition to forest characteristics, the capacity of UAV photogrammetry to model terrain under vegetation also relies on the structure from motion (SfM) algorithm utilized, the point density, and the classification of the 3D point cloud [20,34,35]. The point cloud classification process can be carried out both manually and automatically. Once classified, terrain points may be interpolated to generate a DTM [36]. However, few studies have assessed the quality of the DTM acquired by different classification procedures and its potential to estimate the structural features of forest stands during initial growth stages [37].

One may utilize two approaches to estimate vegetation characteristics from 3D remote sensing products and traditional field survey data: (i) the area-based approach (ABA) [38] and (ii) individual tree detection (ITD) $[39,40]$. Both approaches have benefits and drawbacks, as their usage is dictated by 3D data properties, available field data, allometric models and vegetation type. For ABA, each field plot is considered as a unit of analysis. On the other hand, for ITD, each tree is considered a unit of analysis, and direct/derived estimates of their characteristics are determined by metrics extracted from the point cloud of each identified tree [41]. Subsequently, their estimates may be extrapolated to plot or stand levels [17].

Given the high quality of current 3D remote sensing products (LiDAR and DAP) and the unprecedented processing capabilities provided by cloud-based platforms, applications focused on individual tree detection and height estimation are becoming increasingly more 
common $[16,42,43]$. However, in most studies published to date, the validation of tree detection is not performed with accurate location data obtained directly in the field by realtime kinematic (RTK) positioning or total station (see Guerra et al. [24] and Krause et al. [44] for exceptions). In addition, tree heights are usually compared with indirect field-based estimates subject to measurement errors, which are usually not quantified $[45,46]$. Few studies have shown the DAP-UAV's potential to detect individual trees and estimate height in young Eucalyptus plantations for the purpose of qualitative forest inventory. Hentz et al. [37] explored this gap, but precise measurements of tree location and direct tree height measurements were not used to validate the results. Studies that evaluate the quality of DTMs and other DAP-UAV products in young Eucalyptus stands are also missing.

In this study, we assessed the potential of UAV photogrammetry data to detect individual trees, estimate their heights, and monitor the initial silvicultural quality of a young Eucalyptus sp. stand in northeastern Brazil. DAP estimates were compared with accurate tree locations obtained with RTK positioning and direct height measurements obtained in the field, with known measurement errors. In addition, we assessed the quality of a DAPUAV DTM derived with an alternative ground classification approach and investigated its performance in the retrieval of tree attributes.

\section{Materials and Methods}

\subsection{Study Area}

The study area comprised a 0.15 ha Eucalyptus grandis stand located in the municipality of São Cristóvão, Sergipe, Brazil $\left(-10.924^{\circ} \mathrm{S},-37.196^{\circ} \mathrm{W}\right)$ (Figure 1$)$. The tree spacing was $3 \mathrm{~m} \times 2 \mathrm{~m}$ and the stand was 1.5 years old at the time of data collection. The region's climate is classified as tropical wet and dry (As), with a dry summer and the driest month with a rainfall of less than $60 \mathrm{~mm}$ (less than $4 \%$ of the total annual precipitation) [47]. In the region, the mean annual precipitation is $1200 \mathrm{~mm}$, concentrated between April and September, and the mean air temperature is $30^{\circ} \mathrm{C}$ [48]. The soil is classified as red yellow argisol [49], and the terrain is considered smooth, with an elevation of $11.8 \mathrm{~m}$ above sea level and a slope of less than $5 \%$.

\subsection{Forest Inventory Data}

For this study, 214 trees were measured in August 2018. All trees were geolocated using a Trimble ${ }^{\circledR}$ R8s Integrate GNSS System Antenna with a dual-frequency real time kinematic (RTK) receiver (Trimble, Sunnyvale, CA, USA) (https:/ / geospatial.trimble.com/, accessed on 25 March 2021). Coordinates of the basis of the trees $\left(X_{R T K}, Y_{R T K}\right.$ and $\left.Z_{R T K}\right)$ were recorded following the UTM projection (zone $24 \mathrm{~S}$ ), with the SIRGAS2000 Datum.

The mean root mean square error (RMSE) of tree geolocation was $\pm 0.017 \mathrm{~m}$ for $X_{R T K}$ and $Y_{R T K}$ (horizontal position) and $\pm 0.024 \mathrm{~m}$ for $Z_{R T K}$ (elevation). A DTM of the stand was derived by the interpolation of the 214 measures of $Z_{R T K}$ and was labelled as DTM_RTK. The values of $Z_{R T K}$ were interpolated using the triangulated irregular network (TIN) method, which was available on the open-source software QGIS [50].

The total height $\left(h t_{\text {Field }}, \mathrm{m}\right)$ of each tree in the field was measured with the aid of a graduated ruler of $6 \mathrm{~m}$. The ruler was placed vertically beside each plant by a field assistant and the readings were carried out at a distance of approximately $5 \mathrm{~m}$ by an experienced observer. The maximum tree height measured was $5.4 \mathrm{~m}$ (Table 1) and all tree tops were clearly visible to the observer, who stood between planting lines. At the end of the inventory, 37 trees $(17 \%)$ were randomly selected and had their $h t_{\text {Field }}$ remeasured by the same observer. The paired measures were used to estimate the measurement error for $h t_{\text {Field }}$, following the methods of Gonçalves et al. [51]. Errors were estimated and described in total (root mean square deviation, RMSD), systematic (bias) and random (standard deviation, SD) terms. Table 1 presents a summary of $h t$ values measured in the field and the associated errors. 


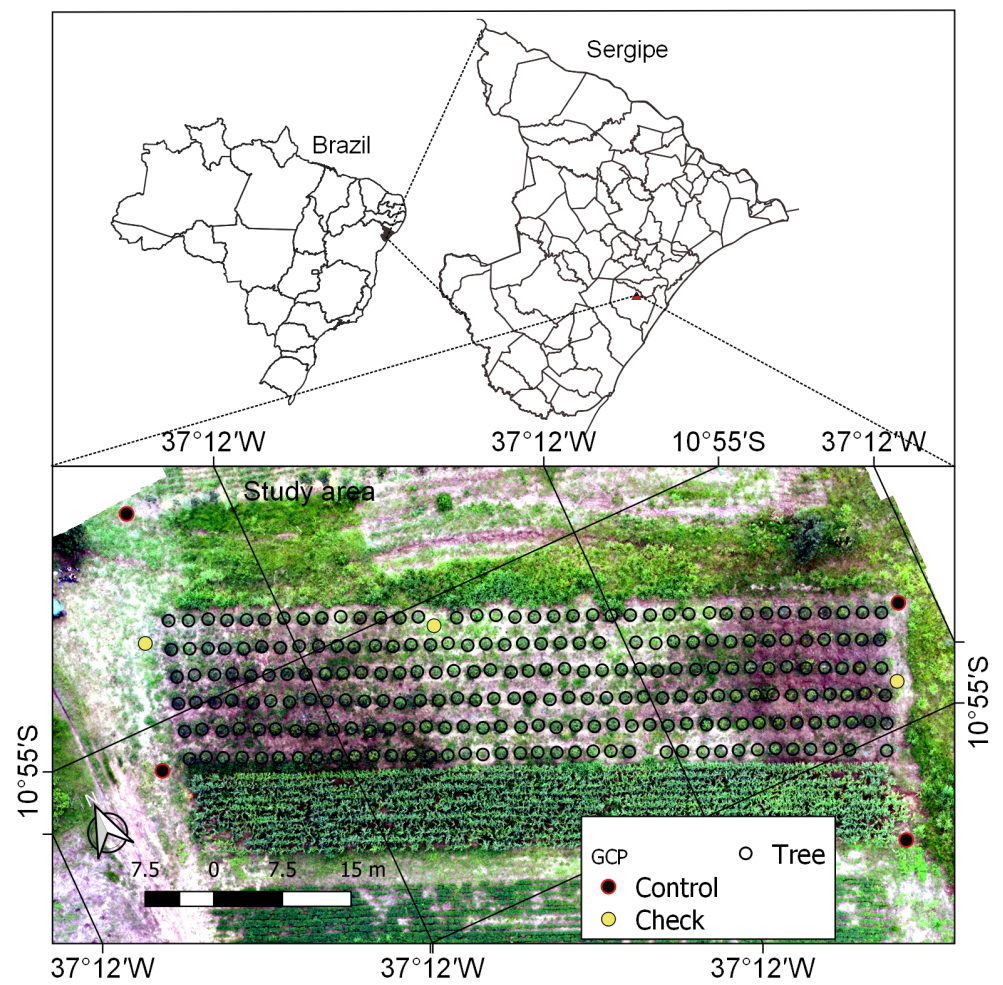

Figure 1. Location of the study area, highlighting tree identification and Ground Control Points (GCPs).

Table 1. Summary of total heights $(h t)$ measured in the young Eucalyptus stand and the associated measurement errors (all values in meters).

\begin{tabular}{llll}
\hline \multicolumn{4}{c}{$\boldsymbol{h t}_{\text {Field }}$ Statistics } \\
\hline Measurements & & Errors \\
\hline Minimum & 0.6 & Range & $0.8-4.6$ \\
Median & 3.35 & RMSD & \\
Mean & 3.34 & Bias $^{1}$ & $0.08(3.0 \%)$ \\
Maximum & 5.4 & SD $^{2}$ & $0.02(0.7 \%)$ \\
\hline
\end{tabular}

${ }^{1}$ Root Mean Square Deviation; ${ }^{2}$ Standard Deviation.

\subsection{Silvicultural Quality of the Stand}

Silvicultural quality was estimated using uniformity indices calculated from $h t$ values. Four indices were utilized to describe the uniformity of the stand: coefficient of variation $(C V)$ of the total heights, Gini index (Gini), canopy relief ratio (CRR), and percentage of cumulative heights for the $50 \%$ lowest trees (PV50). A plot with a Lorenz curve was also utilized to assess the silvicultural quality of the stand [4].

In general, stand uniformity is related to lower coefficients of variation. The $C V$ was estimated as:

$$
C V=\frac{\sqrt{\frac{\sum_{i=1}^{n}\left(h t_{i}-h t_{\text {mean }}\right)^{2}}{(n-1)}}}{h t_{\text {mean }}}
$$

where $i$ is the tree index, $n$ is the number of trees in the plot, $h t_{\text {mean }}$ is the mean plot-level height, and $h t_{i}$ is the height of the $i$-th tree. 
The Gini is also utilized to estimate the variance in tree heights in a forest stand. In its minimal value (zero), all trees have the same height, while in its maximum value (one), all trees except one have the same height [52-54]. The Gini index was estimated as:

$$
\text { Gini }=\frac{\sum_{r=1}^{n}(2 t-n-1) h t_{r}}{\sum_{r=1}^{n} h t_{r}(n-1)}
$$

where $h t_{r}$ is the height of the tree in rank $r$, where $\mathrm{r}$ is the rank of all trees ordered by total height $(1,2,3, \ldots, n)[52,55,56]$.

The CRR describes the relationship between total height extremes (minimum and maximum) and the mean value of all heights. The closer to its maximum value (one), the more uniform the stand; the closer to the minimum value (zero), the less uniform the stand. $C R R$ was estimated as:

$$
C R R=\frac{h t_{\text {mean }}-h t_{\text {min }}}{h t_{\max }-h t_{\min }}
$$

where $h t_{\text {mean }}, h t_{\text {min }}$, and $h t_{\text {max }}$ are, respectively, mean, minimum, and maximum tree total heights.

The PV50 can be utilized to describe the uniformity of the stand [3]. The closer the index is to its maximum value (50\%), the more uniform the stand. PV50 was estimated by sorting $h t$ in ascending order, and using the equation:

$$
P V 50=\frac{\sum_{i=1}^{n / 2} h t_{r 50}}{\sum_{i=1}^{n} h t_{r 50}}
$$

where $h t_{r 50}$ is the total height of the tree in rank $r 50$, where $r 50$ is the rank of the 50 smallest trees ordered by height.

The Lorenz curve was plotted as the cumulative frequency of the number of trees in the stand (horizontal axis) by the cumulative percentage of $h t$ values, from the smallest tree to the tallest one (vertical axis).

\subsection{Digital Aerial Photogrammetry}

\subsubsection{UAV Data Collection}

Using a DJI Phantom 4 PRO quadcopter UAV (SZ DJI Technology Co., Ltd., Shenzhen, China), 70 high-resolution aerial photographs were taken during a field campaign. Imagery were acquired on August 1st 2018 (10:00 a.m local time), using a compact RGB digital camera with a 20 megapixel CMOS sensor and a resolution of $5472 \times 3648$. The camera was installed on a stabilized gimbal to reduce the impact of mechanical vibrations. Meteorological conditions were clear sky (cloud cover $<5 \%)$ and light winds $\left(<10 \mathrm{~m} \mathrm{~s}^{-1}\right)$, following the recommendations of Dandois et al. [30]. The flight was performed $50 \mathrm{~m}$ above ground, using the visual line of sight (VLOS) method, as determined by the Brazilian UAV piloting standards (https: / www.anac.gov.br, accessed on 11 March 2021). Photographs were recorded using the JPG format, with $85 \%$ frontal and side overlap rates. The flight duration was about six minutes, representing almost half of the maximum duration of a flight with a fully charged battery. With one hectare of mapped area, the setup achieved a performance of two hectares per flight/battery.

\subsubsection{Structure from Motion Processing}

Structure from motion (SfM) processing was performed using the Agisoft Metashape Professional Edition 1.6 (https: / / www.agisoft.com, accessed on 15 April 2021) software. For photo alignment, the accuracy parameter was set as "high", with pair pre-selection as "generic" and limits of 40,000 key points and 7000 tie points. Four ground control points (GCPs) were used to georeference the aerial photographs and three complementary GCPs were used to determine the geolocation accuracy (Figure 1). GCPs were randomly distributed throughout the stand. All GCPs were measured using an RTK system, fol- 
lowing the UTM projection (zone 24 S) with SIRGAS2000 Datum. The RMSE obtained for point geolocation was $\pm 0.016 \mathrm{~m}$ for $\mathrm{x}$ and $\mathrm{y}$, and $\pm 0.023 \mathrm{~m}$ for $\mathrm{z}$. After alignment, the georeferencing error was $\pm 0.03 \mathrm{~m}$ for $\mathrm{x}$ and $\mathrm{y}, \pm 0.1 \mathrm{~m}$ for $\mathrm{z}$, and $\pm 0.11 \mathrm{~m}$ for the total error ( $x, y$ and $z)$.

To create the dense cloud point (around 2200 points $\mathrm{m}^{-2}$ ), the parameters were set as "high" for quality and "mild" for depth filtering mode. The mean theoretical ground sample distance (GSD) obtained was approximately $2 \mathrm{~cm}$. The point cloud was then exported following the public 3D Point cloud format LAS (https:/ / www.asprs.org, accessed on 15 April 2021).

\subsubsection{Digital Terrain Model}

The first DTM UAV, labelled as DTM_UAV 1 , was generated using the TIN interpolation of 3D cloud points identified as terrain by an unsupervised classifier. For this step, we used an unsupervised classification algorithm developed by Axelsson et al. [36], which is available on the Agisoft metashape software ("Classify Ground Points" function). The algorithm divides the point cloud into regular grids, and the lowest points within the grid area are processed using the TIN method. Next, the remaining points within the grid are classified in relation to the linear distance to the face of the nearest triangle and the angle formed with the vertices of the initial TIN triangular faces. Points with distances and angles lower than a given threshold are labeled as terrain and a new TIN is generated based on the initial TIN. New TINs are iteratively created until no more points are labeled as terrain. For this procedure, we adopted a cell size of $5 \mathrm{~m}$, a horizontal distance threshold of $1 \mathrm{~m}$, and an angle of $15^{\circ}$.

The second DTM UAV, labeled as DTM_UAV 2, was generated by the interpolation of 3D point clouds manually classified as terrain. Using the function "Select Points by Color", available on the Agisoft Metashape software, 30 representative ground points were selected in the point cloud and used as a training set for the automatic classification of terrain. Points were classified as terrain if they presented an absolute difference (tolerance) in the RGB values of less than two units. The DTM was then generated using the TIN method. All UAV_DTMs were exported as raster files with a spatial resolution of $0.2 \mathrm{~m}$.

\subsubsection{Tree Tops Detection}

To accurately detect trees and determine their heights, the point cloud must undergo a normalization process. The normalization compensates for terrain effects and provides an elevation baseline to retrieve the heights of each detected tree. The point cloud is normalized by subtracting the elevations of a DTM from the elevations of each point within the point cloud. In this study, the point cloud was normalized by subtracting the DTM_RTK, DTM_UAV 1 and DTM_UAV 2 , generating the normalized point clouds (NPC) NPC_RTK, $\mathrm{NPC}_{-} U A V_{1}$, and NPC_UAV 2 , respectively. Tree tops $\left(\mathrm{X}_{U A V}\right.$ and $\left.\mathrm{Y}_{U A V}\right)$, and their total heights $\left(H_{\text {max }}\right)$, were then identified on each NPC utilizing the local maximum filter (LMF) algorithm [57] implemented on the lidR package [58] of the $R$ programming language [59]. The algorithm received each NPC, a $1.5 \mathrm{~m} \times 1.5 \mathrm{~m}$ circular detection window and a minimum tree height of $0.6 \mathrm{~m}$ (minimum $h t$ measured in the field, Table 1) as input. In order to validate the tree detection step, a map of tree crowns was generated through visual interpretation of an RGB orthomosaic of the study area by an experienced GIS analyst. An orthomosaic was generated using the DTM_UAV 1 and exported following a raster format with spatial resolution of $0.2 \mathrm{~m}$.

\subsection{Digital Aerial Photogrammetry Assessment}

\subsubsection{DTM_UAV}

To assess the quality of the DTMs generated from the point cloud, we used elevation measurements obtained in the field with the aid of an RTK system. The measurements reflect the elevations of 214 trees recorded during the tree geolocation step. Measured (RTK) and estimated (DTMs) values were compared using a paired sample $t$-test with 
a significance level of 5\%, along with the determination of RMSE and bias, as well as descriptive statistics of the differences. A DTM generated from the RTK measurements was also subtracted from each DTM in the point cloud. The results were then compiled as maps for further evaluation.

\subsubsection{Tree Tops Detection}

The quality of each NPC was assessed by determining the accuracy of the detection of the tree tops, calculating the percentage of the correctly detected trees $(C D)$ and the relative omission $(O E)$ and commission $(C E)$ errors:

$$
\begin{aligned}
& C D=\frac{N_{\text {detected }}}{N_{\text {observed }}} \\
& O E=\frac{N_{\text {missed }}}{N_{\text {observed }}} \\
& C E=\frac{N_{\text {extra }}}{N_{\text {observed }}}
\end{aligned}
$$

where $N_{\text {detected }}$ is the number of correctly detected trees, $N_{\text {missed }}$ is the number of undetected trees, $N_{\text {extra }}$ is the number of trees detected where there were no trees in the field, and $N_{\text {observed }}$ is the number of trees observed in the field.

A tree top was considered correctly detected when the LMF algorithm placed it inside the polygon representing the crown of the given tree. In cases where more than one tree was placed inside a crown polygon, the point closest to the field location was considered for the $C D$ calculation. The detection step was also assessed by the RMSE between the positional coordinate values $\left(\mathrm{X}_{R T K}\right.$ and $\left.\mathrm{Y}_{R T K}\right)$ of each tree and the estimated coordinates of their tops $\left(\mathrm{X}_{U A V}\right.$ and $\left.\mathrm{Y}_{U A V}\right)$.

\subsubsection{Tree Height}

The total heights of trees automatically identified by each cloud point $\left(H_{\max }\right)$ were compared to the respective heights measured in the field $\left(h t_{\text {Field }}\right)$. The accuracy was assessed using $R^{2}$, RMSE, and bias metrics, along with the mean, maximum, minimum, median, and standard deviation of the differences.

\subsection{Modeled Heights}

A linear regression model $\left(h t_{U A V}=\alpha+\beta H_{\max }+\varepsilon_{i}\right)$ was used to estimate $h t$ values as a function of the $H_{\max }$ obtained from the best NPC, all in meters. The normality of the residuals was evaluated using the Shapiro-Wilks test with a significance level of 5\%.

\subsection{Stand Silvicultural Quality via DAP-UAV}

Using $H_{\max }$ and $h t_{U A V}$ values estimated from the best UAV NPC, the silvicultural quality of the stand was estimated ( $C V$, Gini, CRR, PV50 and Lorenz curve) and compared to values obtained in the traditional field inventory. In addition, maps of individual heights were generated for the entire stand: (i) plotting $X_{R T K}$ and $Y_{R T K}$ coordinates of each tree, associated with $h t_{\text {Field }}$ values, and (ii and iii) plotting $X_{U A V}$ and $Y_{U A V}$ coordinates associated with $H_{\text {max }}$ and $h t_{U A V}$ values, respectively. The visual quality of the estimates and the spatial distribution pattern of tree heights were analyzed and compared to values found in the field.

\section{Results}

\subsection{DAP Assessment}

\subsubsection{DTM_UAV}

Table 2 presents statistics for differences between altitude collected in the field using an RTK system $\left(Z_{R T K}, n=214\right)$ and that estimated from the two DTM_UAVs. Paired sample $t$-tests indicated that RTK and DTM_UAV altitudes did not show statistical differences 
( $p$-value $<0.05)$. Overall, DTM_UAV 2 performed better in estimating $Z_{R T K}$. The comparison between measured and estimated altitude values indicated an overestimation for DTM_UAV 1 , with an average bias of $-0.127 \mathrm{~m}(-1.07 \%)$ and an RMSE of $0.286 \mathrm{~m}(2.43 \%)$. For DTM_UAV 2 , in addition to a lower RMSE value $(0.120 \mathrm{~m}$ or $1.01 \%)$, we observed a negligible underestimation of the altitude values (bias $=0.067 \mathrm{~m}$ or $0.56 \%$ ).

Table 2. Statistics for differences between altitudes collected in the field using an RTK system $\left(Z_{R T K}\right.$, $n=214$ ) and those estimated from two UAV DTMs of a young Eucalyptus stand.

\begin{tabular}{|c|c|c|}
\hline \multirow{2}{*}{ Statistic } & \multicolumn{2}{|c|}{ Elevation Difference $\left(Z_{R T K}-Z_{D T M \_U A V}\right)$} \\
\hline & DTM_UAV $_{1}{ }^{1}$ & DTM_UAV $_{2}{ }^{2}$ \\
\hline Minimum difference (m) & -0.931 & -0.192 \\
\hline Maximum difference (m) & 0.283 & 0.289 \\
\hline RMSE (m) & $0.286(2.43 \%)$ & $0.120(1.01 \%)$ \\
\hline $\operatorname{Bias}(\mathrm{m})$ & $-0.127(-1.07 \%)$ & $0.067(0.56 \%)$ \\
\hline Standard deviation (m) & $0.257(2.18 \%)$ & $0.099(0.84 \%)$ \\
\hline
\end{tabular}

The three selected DTMs and the spatial distribution of the differences between them are shown in Figure 2. The DTM_RTK and DTM_UAV ${ }_{2}$ had similar performances, showing similar elevation values (Figure $2 b, d$ ). DTM_UAV 1 contains vegetation points misclassified as terrain, represented as circular contours. This result may be observed in greater detail by comparing the ellipses in Figure 2a,c.

While Figure $2 b, d$ highlight a clear correspondence between DTM_RTK and DTM_UAV 2 , one may notice a greater dispersion for DTM_UAV $V_{1}$ elevation values $($ range $=2.42 \mathrm{~m})$, as presented in Figure 2c. The largest differences $(0.58$ to $-1.35 \mathrm{~m})$ were found between DTM_RTK and DTM_UAV (Figure 2e), and the smallest ones $(-0.255$ to $0.312 \mathrm{~m}$ ) between DTM_RTK and DTM_UAV 2 (Figure 2f).

\subsubsection{Tree Tops Detection}

The LMF algorithm was able to identify over $95 \%$ of the stand trees within the DAP point cloud (Table 3 and Figure 3). Among the NPC, NPC_RTK and NPC_UAV 2 had the best performance, with approximately $97 \%$ of correctly identified trees (208 and 209 plants, respectively) and virtually no omission and tree duplication errors. Despite its lower performance, NPC_UAV 1 presented a small OE $(5.0 \%)$ and $C E(1.0 \%)$. The smallest tree detected in the plantation was $0.75 \mathrm{~m}$ tall, while the smallest tree measured in the field was $0.58 \mathrm{~m}$.

Figure 3a displays a subset of the stand, indicating tree base locations $\left(\mathrm{X}_{R T K}, \mathrm{Y}_{R T K}\right)$ obtained in the field with RTK (black dots) and their automatically detected tops using each NPC: NPC_RTK (yellow dots), NPC_UAV 1 (white circles), and NPC_UAV 2 (orange circles). Crown areas for each tree, retrieved by visual interpretation of the orthomosaic, are shown as black outlined polygons. Figure 3 presents a high correspondence between tree tops estimated by NPC_RTK (yellow dots) and NPC_UAV 2 (orange circles). RMSE values between tree base and tree top coordinates estimated from NPC_RTK, NPC_UAV 1 , and NPC_UAV 2 were $0.25,0.17$, and $0.15 \mathrm{~m}$, respectively. Figure $3 \mathrm{~b}-\mathrm{d}$ present subsets of these NPCs, which were able to properly represent the vertical structure of the trees. 


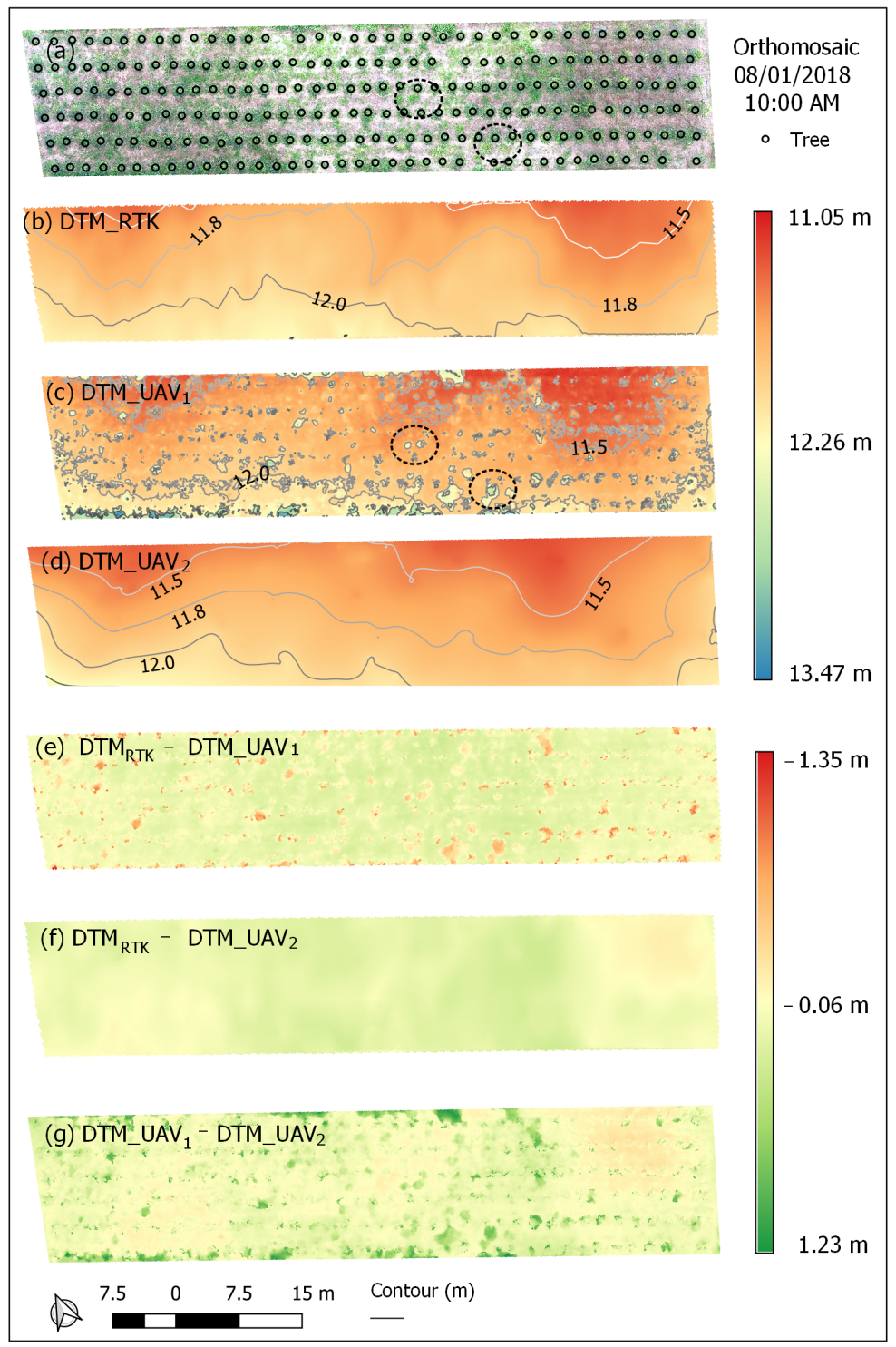

Figure 2. (a) Orthomosaic of the study area; (b) DTM generated from RTK measurements; (c) DTM generated from unsupervised classification of the point cloud; (d) DTM generated from supervised classification of the point cloud; and (e-g) Spatial distribution of differences between the DTMs.

Table 3. Tree detection metrics for each normalized point cloud (NPC) analyzed.

\begin{tabular}{lllll}
\hline Point Cloud & $\boldsymbol{C D}^{\mathbf{1}}$ & $\boldsymbol{O E}^{\mathbf{2}}$ & $\boldsymbol{C E ^ { 3 }}$ & Duplicated Trees \\
\hline NPC_RTK & $208(97.2 \%)$ & $6(2.8 \%)$ & $0(0.0 \%)$ & $0(0.0 \%)$ \\
NPC_UAV $_{1}$ & $204(95.3 \%)$ & $10(4.6 \%)$ & $2(0.9 \%)$ & $2(0.9 \%)$ \\
NPC_UAV $_{2}$ & $209(97.6 \%)$ & $5(2.3 \%)$ & $0(0.0 \%)$ & $0(0.0 \%)$ \\
\hline
\end{tabular}

${ }^{1}$ Percentage of correctly detected trees; ${ }^{2}$ Omission error; ${ }^{3}$ Commission error. 


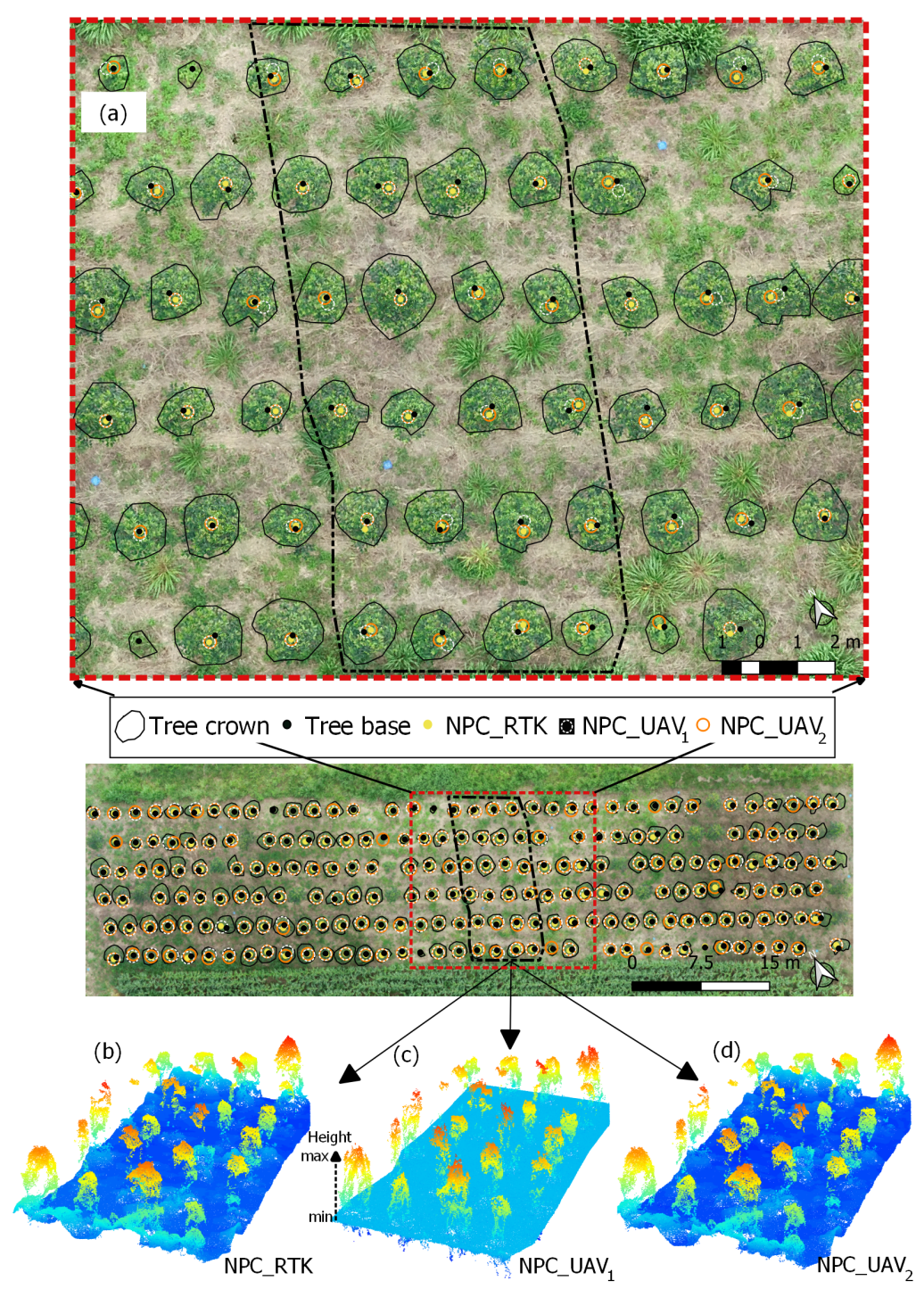

Figure 3. (a) RGB orthomosaic of a young Eucalyptus stand indicating tree crowns mapped through visual interpretation (black outlined polygons), tree bases obtained in the field with RTK (black dots), and three tops detected with three different normalized point clouds: (b) NPC_RTK (yellow dots), (c) NPC_UAV 1 (white circles), and (d) NPC_UAV 2 (orange circles).

\subsubsection{Tree Height}

$H_{\max }$ values obtained from each NPC were compared to $h t_{\text {Field }}$ values (Table 4 and Figure 4). All UAV photogrammetry products led to $h t$ underestimation, with bias ranging from 0.2 to $0.3 \mathrm{~m}$ (Table 4). Underestimation of $h t$, as well as the underestimation of the mean and maximum values for the stand, is also evident on scatterplos and boxplots shown in Figure 4. The worst performance was observed for estimates derived from the NPC_UAV ${ }_{1}$, which presented greater scattering and limitations in the retrieval of the heights of the smallest trees (Figure $4 \mathrm{~b}, \mathrm{~d}$ ). Overall, the best estimates were achieved by the NPC_UAV ${ }_{2}$, which showed smaller RMSE $(0.36 \mathrm{~m}$ or $10.9 \%)$ and bias $(0.22 \mathrm{~m}$ or $6.7 \%)$ (Table 4 and Figure 4). 
Table 4. Statistics of tree height estimates, considering each normalized point cloud (NPC) analyzed.

\begin{tabular}{llll}
\hline \multirow{2}{*}{\multicolumn{1}{c}{ Statistic }} & \multicolumn{3}{c}{$\boldsymbol{h t}_{\text {Field }}-\boldsymbol{H}_{\text {max }}$} \\
\cline { 2 - 4 } & NPC_RTK & NPC_UAV $_{\mathbf{1}}$ & NPC_UAV $_{\mathbf{2}}$ \\
\hline Mean difference (m) & 0.30 & 0.29 & 0.22 \\
Standard deviation (m) & $0.28(8.3 \%)$ & $0.34(9.1 \%)$ & $0.27(8.3 \%)$ \\
Median difference (m) & 0.25 & 0.24 & 0.17 \\
Minimum difference (m) & -0.51 & -0.62 & -0.78 \\
Maximum difference (m) & 1.46 & 1.82 & 1.35 \\
BIAS (m) & $0.30(8.9 \%)$ & $0.29(8.2 \%)$ & $0.22(6.7 \%)$ \\
RMSE (m) & $0.41(12.4 \%)$ & $0.43(12.9 \%)$ & $0.36(10.9 \%)$ \\
\hline
\end{tabular}
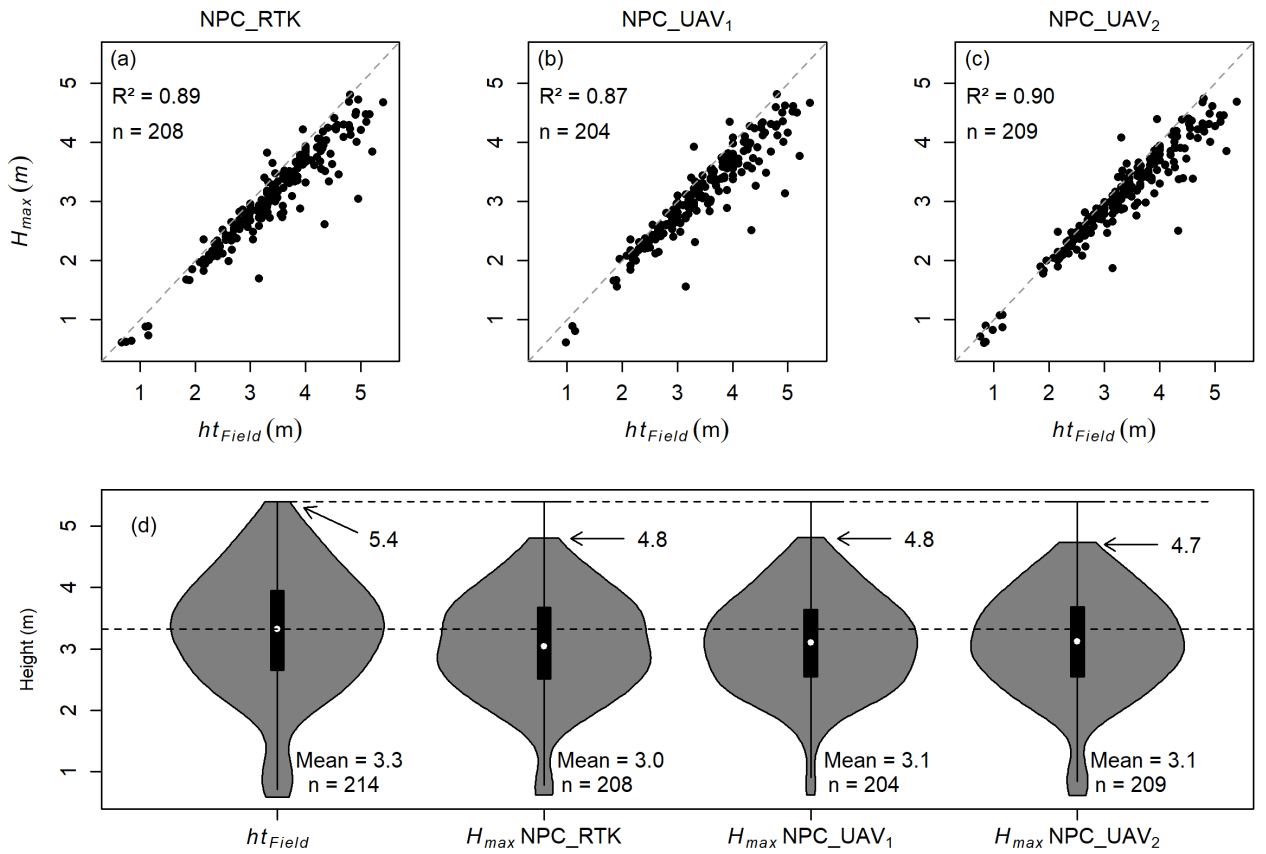

Figure 4. Scatterplots $(\mathbf{a}-\mathbf{c})$ and boxplots $(\mathbf{d})$ of observed $\left(h t_{\text {Field }}\right)$ versus estimated $\left(H_{\text {max }}\right)$ tree heights from UAV photogrammetry, considering three normalized point clouds (NPC). The dashed line in (d) represents the mean value of $h t_{\text {Field }}$.

\subsection{Modelled Tree Height}

A linear regression model was built to estimate $h t$ as a function of $H_{\max }$ values obtained from the NPC_UAV 2 . The predicted $h t$ values were termed $h t_{U A V}$. Compared to heights estimated directly with DAP-UAV (i.e., $H_{\max }$ ), the adjusted regression model improved the accuracy, reducing the RMSE by $20 \%$ (Figure $5 \mathrm{a}$ ). In addition, the model improved the height estimates for the largest trees of the stand (Figure $5 b$ ) and delivered height estimates that were unbiased relative to the field heights. 

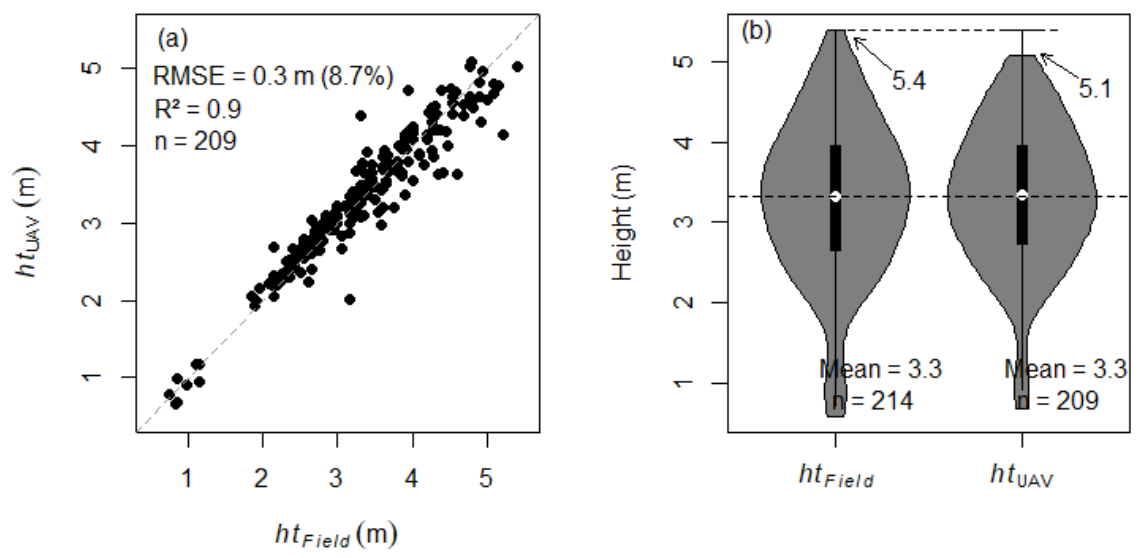

Figure 5. Scatterplot $(\mathbf{a})$ and boxplot $(\mathbf{b})$ of observed $\left(h t_{\text {Field }}\right)$ versus estimated $\left(h t_{U A V}\right)$ tree heights from UAV photogrammetry in a young Eucalyptus stand. The dashed line in (b) represents the mean value of $h t_{\text {Field }}$.

\subsection{Silvicultural Quality of the Stand}

Figure 6 presents the Lorenz curve and stand uniformity metrics estimated from $h t_{\text {Field }}$ (Figure 6a), $H_{\max }$ and $h t_{U A V}$ (Figure 6b). The stand presents a Lorenz curve close to its optimum (line of equality), Gini values close to zero (Gini $=0.16)$, low coefficient of variation $(C V=30 \%$ ), and a $P V 50$ of $38 \%$ (close to its maximum value of $50 \%$ ). There were no significant differences between the silvicultural quality estimated from $h t_{\text {Field }}$ and that estimated from $H_{\max }$ and $h t_{U A V}$.

Field measurement

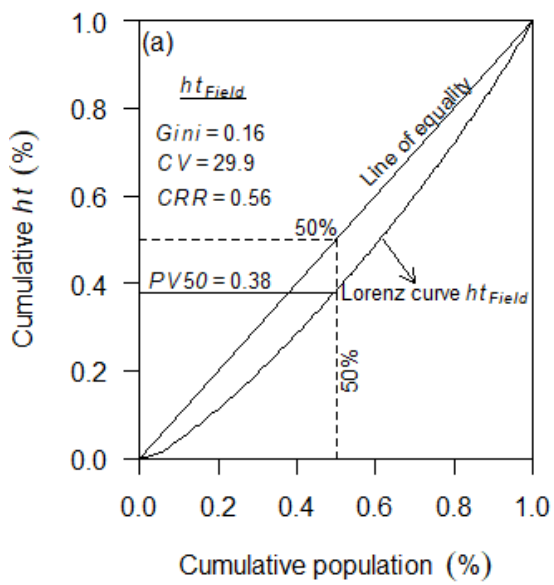

UAV Photogrammetry

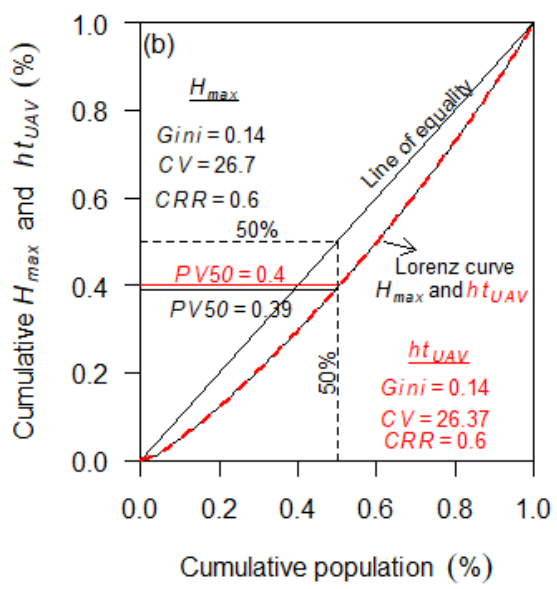

Figure 6. Lorenz curve and uniformity metrics of a young Eucalyptus stand. The metrics are based on tree heights $(h t)$ estimated from (a) traditional field inventory, and (b) UAV photogrammetry data ( $H_{\text {max }}$ in black and $h t_{U A V}$ in red).

Tree height maps generated from field inventory measurements $\left(h t_{\text {Field }}\right)$ and NPC_UAV 2 data $\left(H_{\max }\right.$ and $\left.h t_{U A V}\right)$ are presented in Figure $7 \mathrm{c}-\mathrm{e}$, along with a RGB point cloud (Figure 7a) and a vertical profile (Figure 7b). The maps highlight the conformity of heights measured in the field and estimated via UAV photogrammetry, suggesting a better performance of $h t_{U A V}$ compared to $H_{\max }$. 


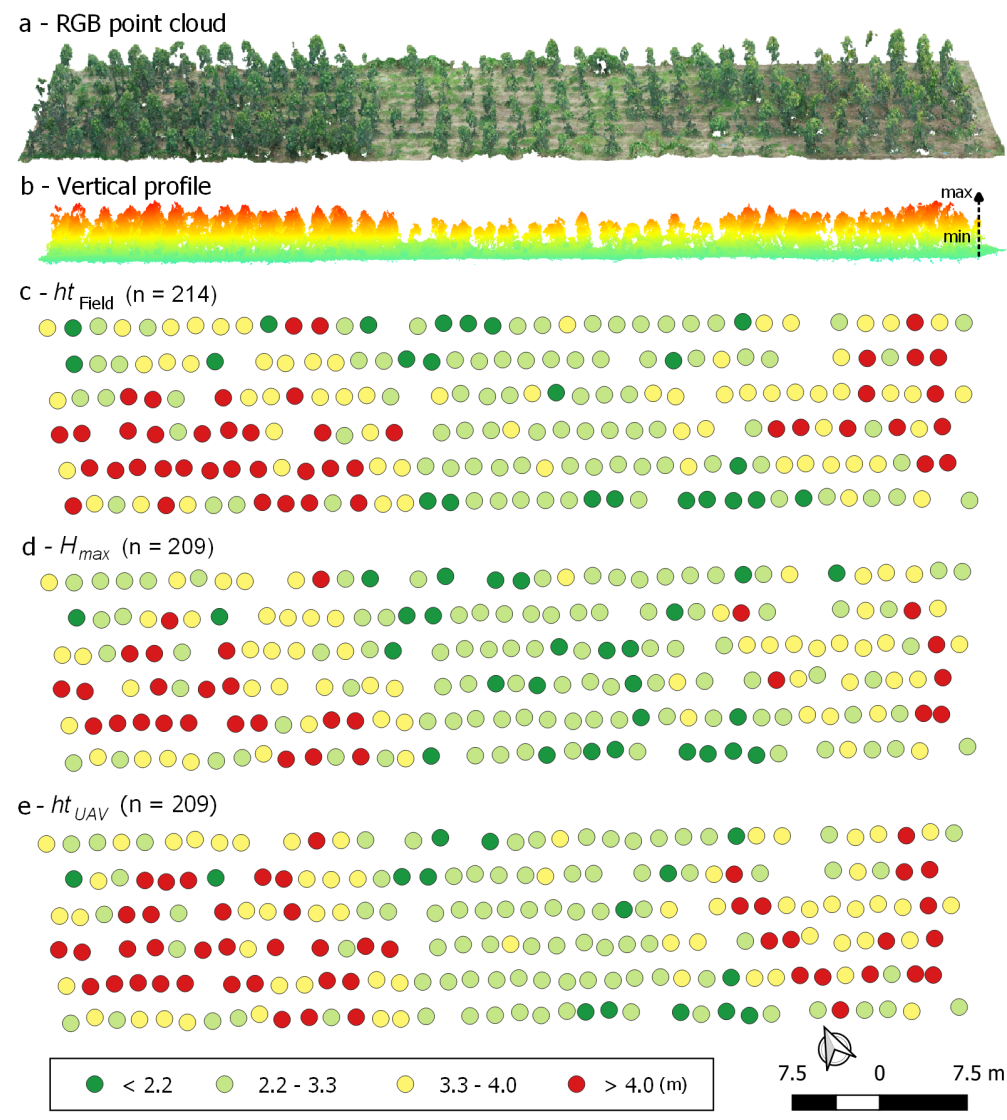

Figure 7. (a) RGB point cloud of a young Eucalyptus stand; (b) the associated vertical profile; and maps detailing the spatial distribution of tree height as (c) measured in the field $\left(h t_{\text {Field }}\right)$ and $(\mathbf{d}, \mathbf{e})$ estimated from UAV photogrammetry $\left(H_{\max }\right.$ and $h t_{U A V}$, respectively).

\section{Discussion}

In this study, we evaluated the potential of UAV photogrammetry products to carry out the initial qualitative inventory of a Eucalyptus stand in northeastern Brazil. To retrieve forest structural information from DAP-UAV products, we utilized an approach based on individual tree detection (ITD) [39,40]. Its success relies on the correct identification of tree tops and a precise estimation of their heights $[44,60,61]$. Therefore, the method is sensitive to the quality of the DAP products, the efficiency of the identification method, and the physical properties of the area under analysis [62-65].

\subsection{DTMs Assessment}

Our results indicate the efficacy of DAP-UAV products to model terrain in young Eucalyptus stands. UAV photogrammetry products may present limitations to modelling the terrain under vegetation $[29,66-70]$, with DTMs commonly overestimating the elevation under the forest, leading to underestimation of tree heights [30,31]. In contrast to LiDAR, DAP cannot penetrate the forest canopy and describe the vertical profile of the vegetation in detail [23]. Limitations emerge from different sources, such as hardware (cameras), software (SfM algorithms), flight parameters (height, overlap rate, viewing angle), and physical properties of the area (terrain and vegetation) [30,71]. Therefore, knowledge of the accuracy of DAP-UAV products is crucial for success in forest applications [72].

The low canopy relief ratio $(C R R=0.56)$ of the stand, primarily determined by its wide plant spacing $(3 \mathrm{~m} \times 2 \mathrm{~m})$, led to an adequate representation of the terrain and lower estimation errors. Several studies indicate that DAP-UAV products are suitable for modelling terrain under sparse forest formations [28,71,73,74]. Similar results were observed by Aguilar et al. [75] in a survey conducted to assess the quality of DTMs 
generated with DAP data for a Tectona grandis stand located in the coastal region of Ecuador. In addition to the low $C R R$, the smooth terrain $(<5 \%)$ of the study area contributed to the quality of the DAP-UAV products, as studies have shown that UAV photogrammetry products perform better in flat areas [71,74].

Proper identification of terrain points has a direct impact on the quality of the generated DTMs $[35,76]$. In this study, terrain models generated from supervised classification of the 3D point cloud (DTM_UAV ${ }_{2}$ ) achieved the highest compatibility (RMSE $=0.12 \mathrm{~m}$ or $1.01 \%$ ) with data collected in the field (Figure 2f) using an RTK system (DTM_RTK). In the absence of LiDAR, DTMs generated from RTK surveys may be employed to normalize $3 \mathrm{D}$ point clouds [66]. However, RTK data may not be cost-effective because limitations on GNSS signal reception may compromise its usage under dense vegetation conditions [44]. The supervised classification procedure (DTM_UAV $)_{2}$ ) described in this study enabled accurate identification of terrain points and reduction in errors introduced by artifacts from misclassified vegetation points (DTM_UAV 1 , Figure 2c). Elevation values of both models did not show a statistically significant difference ( $p$-value $>0.05$, paired $t$-test) in relation to the RTK elevations obtained in the field.

The supervised classification increased the quality of DAP products, highlighting the potential of DAP-UAV data for areas with sparse vegetation. Nevertheless, in sites with different types and colors of soils, this method may not represent the variation well if a small number of points is used for training. However, although not tested in this study, we expect that a large sample size, covering all the color variation in an area, may still produce good results. In these cases, setting a higher tolerance limit $(>2)$ may also help with the ground classification. The supervised classification requires an extra step that cannot be easily automated and will unavoidably increase the processing time. Although the added time may not be significant for occasional or small-area inventories, it will add up in continuous, large-scale inventories. However, for the operational inventory of Eucalyptus stands, alternatives can be used to reduce the total processing time. For instance, once the terrain is mapped when the soil is visible during pre-planting operations, the DTM generated by either supervised or unsupervised classification can be used as the reference for the normalization of point clouds generated in future acquisitions, when the vegetation is present. In addition, if a good LiDAR, InSAR or topography-based DTM is available, it can also be used as the reference surface for normalization in future UAV acquisitions.

Small shrubs and decomposing organic material compromised the proper representation of the terrain in the DTM_UAV 1 (contour lines in Figure 2c). This behavior is similar to that found by Fawcett et al. [77] when generating a DTM from DAP-UAV data in a stand of Elaeis guineensis in the state of Sarawak, Malaysian Borneo. The terrain reconstruction errors found in our study are also similar to those observed for LiDAR data in areas with deciduous forest and small shrubs and trees in South Carolina, United States [78]. The cost of a UAV photogrammetry survey represents one third to half the cost of a LiDAR survey $[79,80]$. This economical aspect, together with its enormous potential, makes UAV surveys an important alternative to terrain mapping in forest plantation areas. Goodbody et al. [23] point out that strengths of DAP products include their ability to acquire data at high flight altitudes and speeds, increasing the mapped area and reducing costs. The lower costs of UAV data allow for the continuous monitoring of forests [81], thus supporting planning and management practices and filling gaps between strategic, tactical, and operational aspects of the inventory $[79,82]$.

\subsection{Tree Tops Detection}

The normalization process transforms elevation into height by subtracting the DTM from the 3D point cloud [83]. Tree tops and their respective heights can then be automatically located and estimated using normalized point clouds and segmentation algorithms [57,84]. Therefore, the quality of the generated DTMs directly influences tree identification [35]. The NPC and LMF algorithms employed in this study were capable of identifying tree tops $\left(\mathrm{X}_{U A V}, \mathrm{Y}_{U A V}\right)$ in the stand with over $95 \%$ accuracy (Table 3 and Figure $\left.3 \mathrm{a}\right)$. This result 
is similar to that observed by Hentz et al. [37] ( $C D=93.5 \%)$ in a study to identify young plants ( 1.5 years old) in Pinus and Eucalyptus stands in Paraná, Brazil, and better than that found by Fawcett et al. [77] ( $C D=80.4 \%)$ for the identification of trees in a two-year-old palm plantation in Sarawak, Malaysian Borneo.

The quality of the tree top identification process (Figure 3a) was supported by the low RMSE values $(<0.25 \mathrm{~m})$ observed between estimated $\left(\mathrm{X}_{U A V}, \mathrm{Y}_{U A V}\right)$ and measured $\left(\mathrm{X}_{R T K}, \mathrm{Y}_{R T K}\right)$ coordinates. $\mathrm{Yu}$ et al. [85], using LiDAR to identify trees in a boreal forest in southern Finland, found smaller location differences than those observed in our study $($ RMSE $=0.04 \mathrm{~m})$. The overall better performance of LiDAR is related to its penetration capacity, reaching the ground and the baseline plant level.

The best performance in tree top detection was achieved through the cloud normalized by DTM_UAV 2 (Table 3 ). The performance is directly related to low errors observed in DTM_UAV 2 achieved by the supervised classification of terrain points. It is noteworthy that in contrast to previous studies [31,37,43], the effect of the tree top detection window parameters were not assessed. For future research, we suggest the assessment of different DAP-UAV point cloud densities, crown shapes, and detection window sizes, as well as different identification methods.

\subsection{Tree Height}

All UAV photogrammetry products delivered adequate tree height estimates (bias $<0.3 \mathrm{~m}$ and RMSE $<0.43 \mathrm{~m}$ or $13 \%$ ). However, $h t$ values were systematically underestimated, even with the point cloud normalized using the DTM generated with RTK measures (NPC_RTK). The accuracy of $h t$ estimated in our study was similar to that found by Hentz et al. [37] while estimating tree heights of a young Eucalyptus plantation using DAP-UAV data (RMSE $=0.44 \mathrm{~m}$ ). In a 7-year-old Eucalyptus plantation, GuerraHernández et al. [25] also observed an underestimation of individual $h t$ values, with an RMSE and bias of $2.84 \mathrm{~m}$ and $2.67 \mathrm{~m}$, respectively. Our results were also similar to those observed by Krause et al. [44] (RMSE $=0.49 \mathrm{~m}$ or $2.78 \%$ and bias $=0.365 \mathrm{~m}$ or $2.21 \%$ ), who estimated individual $h t$ using DAP-UAV and a DTM obtained by RTK in a wild pine stand in northeastern Berlin, Germany. In that study, photogrammetric tree height measurements were validated using destructive methods. Studies conducted with LiDAR data also show a tendency to underestimate $h t$ values $[17,25,81]$. Comparing $h t$ values derived by LiDAR with field measurements of young Eucalyptus stands ( $<4$ years) in southeastern Brazil, Leite et al. [17] found a RMS error of $11.98 \%$ and a bias of $11.17 \%$.

Despite being able to explain about $90 \%\left(\mathrm{R}^{2}=0.87\right)$ of the $h t$ variation, the NPC_UAV 1 performed worse $(O E=10$ trees or $4.6 \%)$ in identifying and estimating the height of the smallest trees $(h t<1 \mathrm{~m})$, as a result of the inferior quality of the DTM_UAV 1 (Table 2 and Figure 2c,e). We, therefore, recommend the use of the DAP point cloud normalized by a DTM generated with a supervised classification of terrain points. The low accuracy of DTMs is considered by many authors to be the main source of uncertainty regarding tree height estimation using DAP-UAV data $[28,66,69,86]$. Given the reduced bias for elevations $\left(Z_{\text {RTK }}\right)$ measured at the base of each plant $(-1.07 \%$ in DTM_UAV 1 and $0.56 \%$ in DTM_UAV 2 , Table 2), there is no evidence that the DTMs generated in this study were responsible for the underestimation of tree heights $(h t)$. The uncertainties associated with $h t_{\text {Field }}$ measures can also be discarded as a source of the observed errors (Table 1). The underestimation of $h t$ is likely related to difficulties in reconstructing the upper part of the tree tops using DAP techniques [87]. This hypothesis is supported by the small differences between the maximum $h t$ and the maximum heights estimated with each NPC $(0.65 \mathrm{~m}$ in average) (Figure 4d). Cunliffe et al. [87] also reported issues with dense 3D point clouds when modelling vegetation heights in the semiarid region of New Mexico, United States. Studies show that height underestimation is more frequent when DAP-UAV products are collected in sparse areas, such as forest stands in early stages of development [88,89]. Evaluating different techniques to collect and process 3D vegetation data, Crespo-Peremarch et al. [90] found that the SfM algorithm and the parameters used influence the quality of the DTM 
and, consequently, the subsequent UAV photogrammetry products. Therefore, we suggest that different SfM algorithms and parameters are tested upon photo alignment.

Crown movements caused by wind may have led to failures in the identification of key and tie points. In consonance with the study by Dandois et al. [30], we suggest that UAV surveys are performed only when the wind speed is under $8 \mathrm{~m} / \mathrm{s}$. We also suggest further research into methods to identify tree tops that utilize unnormalized point clouds as input data, since the normalization process may impact the reconstruction of tree tops [91]. We also expect that angular and rotational variation in UAV imaging has the potential to improve tree identification and DTM quality because different viewing angles increase the chance of seeing the ground and facilitate the identification of key and tie points. Therefore, we recommend that this feature be evaluated.

Diverging from the observed by Krause et al. [44], we found that $h t$ estimated directly from the DAP-UAV point cloud $\left(H_{\max }\right)$ led to a higher RMSE and bias than those found for the field inventory, as estimated from repeat measures (Table 1). Nevertheless, it is noteworthy that the measurement errors observed in our study are low because of the small scale of the experiment and the usage of a graduated ruler to measure $h t$ directly. Given that tree heights are usually estimated from indirect methods that are less accurate than that used in our study [92-94], the errors for estimates generated from DAP-UAV can be considered satisfactory.

\subsection{Modelled Tree Height}

Regression models are widely used to estimate heights from 3D remote sensing metrics that represent the vertical structure of a forest $[17,31,85,86,89]$. Studies suggest that the use of linear regression models may eliminate biased predictions found in the ITD approach $[60,85]$. Using $H_{\max }$ values estimated from the NPC_UAV ${ }_{2}$, a simple linear regression model was fitted to estimate $h t$ values $\left(h t_{U A V}\right)$ for the analyzed Eucalyptus stand (Figure 5). The model was able to explain $90 \%$ of the $h t$ variation, reducing the RMSE by $20 \%$ (Figure $5 \mathrm{a}$ ). Additionally, the model was able to improve height estimates for the tallest trees (Figure 5b). The performance of the regression model, marked by small errors and unbiased estimates of tree heights, highlights the enormous potential of UAV photogrammetry data to monitor the initial silvicultural quality of Eucalyptus stands.

\subsection{Stand Silvicultural Quality}

Traditionally, the initial silvicultural quality of forest plantations is determined by means of data collected in field campaigns $[3,27,95]$. The usage of DAP-UAV data is still reduced for this purpose, especially for Eucalyptus stands [37,96]. In this study, we found that, regardless of the height estimation procedure (directly via $H_{\max }$ or indirectly via $\left.h t_{U A V}\right)$, the uniformity estimated by DAP-UAV is similar to that found in traditional inventory (Figure 6).

However, a slight tendency to overestimate stand uniformity was found, with lower values for Gini and $C V$ and higher values for CRR and PV50 (Figure 6b). The trend is related to difficulties presented by the DAP technique to identify small trees and estimate maximum $h t$ values (Table 4 and Figure 4), as discussed in the sections above. Figure $7 \mathrm{~d}$,e illustrate the quality of the 3D point cloud and the underestimation of heights, especially for the largest height classes (yellow and red points). One may also verify the improvement in height estimation (Figure 7e) brought by the regression model between $h t$ and $H_{\max }$, particularly for the largest height classes (4.20 to $5.4 \mathrm{~m}$ ).

Finally, we can observe the flexibility of the approach used, allowing for stand characteristics to be estimated and mapped at the tree level. The approach presented in our study may support management and initial protection activities of the stand, assisting rescue, enrichment, and protection activities, in addition to general assessments of the quality in the field. DAP-UAV surveys are low-cost and highly accurate, being a suitable tool for precision silviculture activities in developing countries, such as Brazil. 


\section{Conclusions}

In this study, we assessed an approach to estimate forest attributes at the tree level using UAV photogrammetry data. The approach allows for a direct connection between DAP-UAV data and tree-level measurements obtained in the field. An alternative would be an area-based approach, which inherits the setback of establishing an indirect relation between UAV data and average forest attribute values at the plot level. The results are promising, indicating that UAV photogrammetry data can be employed to identify individual trees, estimate their heights, and evaluate the initial silvicultural quality of Eucalyptus stands. From the results, we conclude that: (i) The terrain model generated from supervised classification of the 3D point cloud achieved the best performance; thus, it is recommended as the preferred approach for terrain modelling by UAV photogrammetry. (ii) The point cloud normalized with the DTM generated from the supervised classification led to the best performance in the automatic detection of tree tops. (iii) Tree heights derived directly from UAV point clouds resulted in underestimation when compared to field measurements. However, a linear regression model based on the maximum UAV heights reduced the RMSE and improved height estimates for the tallest trees. (iv) There were no differences between silvicultural quality metrics estimated from DAP-UAV and field data.

In future research, we suggest evaluating the technique presented in this study for stands on sloping terrain conditions. It is also important that the approach is explored for stands with different ages, plant spacing, management regimes, and genetic materials. We also suggest that studies are carried out with angular and rotational variation in UAV imaging in order to evaluate its impacts on product quality.

Author Contributions: A.A. conceived, designed, and performed the experiment; analyzed the data; and wrote the paper. F.G. assisted with study design, data analysis and writing of the paper. G.S., A.M., M.G., J.S. and R.S. assisted with interpretation of results, and writing of the paper. I.L. assisted with data collection and contributed to parts of the analysis. K.N., M.B. and B.S. assisted with data collection and writing of the paper. All authors have read and agreed to the published version of the manuscript.

Funding: This research was funded by CNPq grant number 310299/2019-5.

Institutional Review Board Statement: Not applicable.

Informed Consent Statement: Not applicable.

Acknowledgments: The authors would like to thank CNPq for the research grant from the first author of the project Models for estimating biomass and other dendrometric characteristics of a secondary forest process 310299/2019-5. Also thank the Rural Campus of the Federal University of Sergipe (UFS), for the logistical support during the fieldwork.

Conflicts of Interest: The authors declare no conflict of interest.

\section{Abbreviations}

The following abbreviations are used in this manuscript:

$\begin{array}{ll}\text { ABA } & \text { Area-based approach } \\ C D & \text { Correctly detected } \\ \text { CO } & \text { Commission Error } \\ C V & \text { Coefficient of Variation } \\ C R R & \text { Canopy Relief Ratio } \\ \text { DAP } & \text { Digital Aerial photogrammetry } \\ \text { DTM } & \text { Digital Terrain Model } \\ \text { GSD } & \text { Ground Sample Distance } \\ \text { GCPs } & \text { Ground Control Points } \\ \text { GPP } & \text { Gross Primary Product } \\ \text { GNSS } & \text { Global satellite navigation systems } \\ \text { ITD } & \text { Individual Tree Detection }\end{array}$




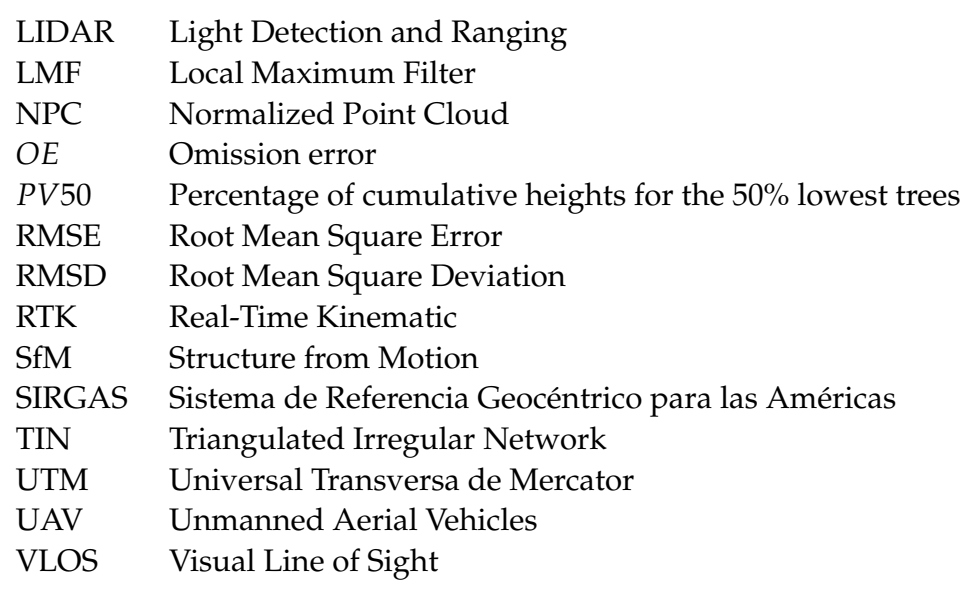

\section{References}

1. Indústria Brasileira de Árvores (IBÁ). Relatório 2019; Technical Report Relatório Anual; OSAC: São Paulo, Brazil, 2019.

2. Tomé, M.; Burkhart, H.E. Distance-Dependent Competition Measures for Predicting Growth of Individual Trees. For. Sci. 1989, 35, 816-831. [CrossRef]

3. Hakamada, R.E.; Stape, J.L.; Lemos, C.C.Z.d.; Almeida, A.E.A.; Silva, L.F. Uniformidade Entre árvores durante uma rotação e sua relação com a produtividade em Eucalyptus clonais. CERNE 2015, 21, 465-472. [CrossRef]

4. Lorenz, M.O. Methods of Measuring the Concentration of Wealth. Publ. Am. Stat. Assoc. 1905, 9, 209-219. [CrossRef]

5. Weiner, J.; Solbrig, O.T. The meaning and measurement of size hierarchies in plant populations. Oecologia 1984, 61, 334-336. [CrossRef]

6. Valbuena, R.; Vauhkonen, J.; Packalen, P.; Pitkänen, J.; Maltamo, M. Comparison of airborne laser scanning methods for estimating forest structure indicators based on Lorenz curves. ISPRS J. Photogramm. Remote Sens. 2014, 95, 23-33. [CrossRef]

7. Valbuena, R.; Maltamo, M.; Martín-Fernández, S.; Packalen, P.; Pascual, C.; Nabuurs, G.J. Patterns of covariance between airborne laser scanning metrics and Lorenz curve descriptors of tree size inequality. Can. J. Remote Sens. 2013, 39, S18-S31. [CrossRef]

8. Burkhart, H.E.; Tomé, M. Modeling Forest Trees and Stands; Springer Science \& Business Media: Dordrecht, The Netherlands, 2012; p. 458.

9. Bauwens, S.; Bartholomeus, H.; Calders, K.; Lejeune, P. Forest Inventory with Terrestrial LiDAR: A Comparison of Static and Hand-Held Mobile Laser Scanning. Forests 2016, 7, 127. [CrossRef]

10. Hyyppä, J.; Hyyppä, H.; Inkinen, M.; Engdahl, M.; Linko, S.; Zhu, Y.H. Accuracy comparison of various remote sensing data sources in the retrieval of forest stand attributes. For. Ecol. Manag. 2000, 128, 109-120. [CrossRef]

11. Næsset, E. Estimating timber volume of forest stands using airborne laser scanner data. Remote Sens. Environ. 1997, 61, 246-253. [CrossRef]

12. Wulder, M.A.; Coops, N.C.; Hudak, A.T.; Morsdorf, F.; Nelson, R.; Newnham, G.; Vastaranta, M. Status and prospects for LiDAR remote sensing of forested ecosystems. Can. J. Remote Sens. 2013, 39, S1-S5. [CrossRef]

13. Beland, M.; Parker, G.; Sparrow, B.; Harding, D.; Chasmer, L.; Phinn, S.; Antonarakis, A.; Strahler, A. On promoting the use of lidar systems in forest ecosystem research. For. Ecol. Manag. 2019, 450, 117484. [CrossRef]

14. González-Ferreiro, E.; Diéguez-Aranda, U.; Miranda, D. Estimation of stand variables in Pinus radiata D. Don plantations using different LiDAR pulse densities. For. Int. J. For. Res. 2012, 85, 281-292. [CrossRef]

15. Packalén, P.; Mehtätalo, L.; Maltamo, M. ALS-based estimation of plot volume and site index in a eucalyptus plantation with a nonlinear mixed-effect model that accounts for the clone effect. Ann. For. Sci. 2011, 68, 1085-1092. [CrossRef]

16. Dalla Corte, A.P.; Rex, F.E.; de Almeida, D.R.A.; Sanquetta, C.R.; Silva, C.A.; Moura, M.M.; Wilkinson, B.; Zambrano, A.M.A.; da Cunha Neto, E.M.; Veras, H.F.P.; et al. Measuring Individual Tree Diameter and Height Using GatorEye High-Density UAV-Lidar in an Integrated Crop-Livestock-Forest System. Remote Sens. 2020, 12, 863. [CrossRef]

17. Leite, R.V.; do Amaral, C.H.; de Paula Pires, R.; Silva, C.A.; Soares, C.P.B.; Macedo, R.P.; da Silva, A.A.L.; Broadbent, E.N.; Mohan, M.; Leite, H.G. Estimating Stem Volume in Eucalyptus Plantations Using Airborne LiDAR: A Comparison of Area- and Individual Tree-Based Approaches. Remote Sens. 2020, 12, 1513. [CrossRef]

18. Gobakken, T.; Bollandsås, O.M.; Næsset, E. Comparing biophysical forest characteristics estimated from photogrammetric matching of aerial images and airborne laser scanning data. Scand. J. For. Res. 2015, 30, 73-86. [CrossRef]

19. Puliti, S.; Gobakken, T.; Ørka, H.O.; Næsset, E. Assessing 3D point clouds from aerial photographs for species-specific forest inventories. Scand. J. For. Res. 2017, 32, 68-79. [CrossRef]

20. Iglhaut, J.; Cabo, C.; Puliti, S.; Piermattei, L.; O'Connor, J.; Rosette, J. Structure from Motion Photogrammetry in Forestry: A Review. Curr. For. Rep. 2019, 5, 155-168. [CrossRef]

21. Almeida, A.; Gonçalves, F.; Silva, G.; Souza, R.; Treuhaft, R.; Santos, W.; Loureiro, D.; Fernandes, M. Estimating Structure and Biomass of a Secondary Atlantic Forest in Brazil Using Fourier Transforms of Vertical Profiles Derived from UAV Photogrammetry Point Clouds. Remote Sens. 2020, 12, 3560. [CrossRef] 
22. Baltsavias, E.P. A comparison between photogrammetry and laser scanning. ISPRS J. Photogramm. Remote Sens. 1999, 54, 83-94. [CrossRef]

23. Goodbody, T.R.H.; Coops, N.C.; White, J.C. Digital Aerial Photogrammetry for Updating Area-Based Forest Inventories: A Review of Opportunities, Challenges, and Future Directions. Curr. For. Rep. 2019, 5, 55-75. [CrossRef]

24. Guerra-Hernández, J.; Cosenza, D.N.; Rodriguez, L.C.E.; Silva, M.; Tomé, M.; Díaz-Varela, R.A.; González-Ferreiro, E. Comparison of ALS- and UAV(SfM)-derived high-density point clouds for individual tree detection in Eucalyptus plantations. Int. J. Remote Sens. 2018, 39, 5211-5235. [CrossRef]

25. Guerra-Hernández, J.; Cosenza, D.N.; Cardil, A.; Silva, C.A.; Botequim, B.; Soares, P.; Silva, M.; González-Ferreiro, E.; Díaz-Varela, R.A. Predicting Growing Stock Volume of Eucalyptus Plantations Using 3-D Point Clouds Derived from UAV Imagery and ALS Data. Forests 2019, 10, 905. [CrossRef]

26. Torresan, C.; Berton, A.; Carotenuto, F.; Gennaro, S.F.D.; Gioli, B.; Matese, A.; Miglietta, F.; Vagnoli, C.; Zaldei, A.; Wallace, L. Forestry applications of UAVs in Europe: A review. Int. J. Remote Sens. 2017, 38, 2427-2447. [CrossRef]

27. Leite, R.V.; Silva, C.A.; Mohan, M.; Cardil, A.; de Almeida, D.R.A.; Carvalho, S.d.P.C.e.; Jaafar, W.S.W.M.; Guerra-Hernández, J.; Weiskittel, A.; Hudak, A.T.; et al. Individual Tree Attribute Estimation and Uniformity Assessment in Fast-Growing Eucalyptus spp. Forest Plantations Using Lidar and Linear Mixed-Effects Models. Remote Sens. 2020, 12, 3599. [CrossRef]

28. Dandois, J.P.; Ellis, E.C. High spatial resolution three-dimensional mapping of vegetation spectral dynamics using computer vision. Remote Sens. Environ. 2013, 136, 259-276. [CrossRef]

29. Wallace, L.; Lucieer, A.; Malenovský, Z.; Turner, D.; Vopěnka, P. Assessment of Forest Structure Using Two UAV Techniques: A Comparison of Airborne Laser Scanning and Structure from Motion (SfM) Point Clouds. Forests 2016, 7, 62. [CrossRef]

30. Dandois, J.P.; Olano, M.; Ellis, E.C. Optimal Altitude, Overlap, and Weather Conditions for Computer Vision UAV Estimates of Forest Structure. Remote Sens. 2015, 7, 13895-13920. [CrossRef]

31. Swinfield, T.; Lindsell, J.A.; Williams, J.V.; Harrison, R.D.; Agustiono; Habibi; Gemita, E.; Schönlieb, C.B.; Coomes, D.A. Accurate Measurement of Tropical Forest Canopy Heights and Aboveground Carbon Using Structure From Motion. Remote Sens. 2019, 11, 928. [CrossRef]

32. Dandois, J.P.; Baker, M.; Olano, M.; Parker, G.G.; Ellis, E.C. What is the Point? Evaluating the Structure, Color, and Semantic Traits of Computer Vision Point Clouds of Vegetation. Remote Sens. 2017, 9, 355. [CrossRef]

33. Zarco-Tejada, P.J.; Diaz-Varela, R.; Angileri, V.; Loudjani, P. Tree height quantification using very high resolution imagery acquired from an unmanned aerial vehicle (UAV) and automatic 3D photo-reconstruction methods. Eur. J. Agron. 2014, 55, 89-99. [CrossRef]

34. Lin, W.; Meng, Y.; Qiu, Z.; Zhang, S.; Wu, J. Measurement and calculation of crown projection area and crown volume of individual trees based on 3D laser-scanned point-cloud data. Int. J. Remote Sens. 2017, 38, 1083-1100. [CrossRef]

35. Alcudia-Aguilar, A.; Martínez-Zurimendi, P.; van der Wal, H.; Castillo-Uzcanga, M.M.; Suárez-Sánchez, J. Allometric Estimation of the Biomass of Musa spp. in Homegardens of Tabasco, Mexico. Trop. Subtrop. Agroecosyst. 2019, 22, 143-152.

36. Axelsson, P. Processing of laser scanner data-Algorithms and applications. ISPRS J. Photogramm. Remote Sens. 1999, 54, 138-147. [CrossRef]

37. Hentz, A.M.K.; Silva, C.A.; Corte, A.P.D.; Netto, S.P.; Strager, M.P.; Klauberg, C. Estimating forest uniformity in Eucalyptus spp. and Pinus taeda L. stands using field measurements and structure from motion point clouds generated from unmanned aerial vehicle (UAV) data collection. For. Syst. 2018, 27, 1. [CrossRef]

38. Næsset, E. Predicting forest stand characteristics with airborne scanning laser using a practical two-stage procedure and field data. Remote Sens. Environ. 2002, 80, 88-99. [CrossRef]

39. Hyyppa, J. Detecting and estimating attributes for single trees using laser scanner. Photogramm. J. Finl. 1999, 16, $27-42$.

40. Strîmbu, V.F.; Strîmbu, B.M. A graph-based segmentation algorithm for tree crown extraction using airborne LiDAR data. ISPRS J. Photogramm. Remote Sens. 2015, 104, 30-43. [CrossRef]

41. Wan Mohd Jaafar, W.S.; Woodhouse, I.H.; Silva, C.A.; Omar, H.; Abdul Maulud, K.N.; Hudak, A.T.; Klauberg, C.; Cardil, A.; Mohan, M. Improving Individual Tree Crown Delineation and Attributes Estimation of Tropical Forests Using Airborne LiDAR Data. Forests 2018, 9, 759. [CrossRef]

42. Liu, G.; Wang, J.; Dong, P.; Chen, Y.; Liu, Z. Estimating Individual Tree Height and Diameter at Breast Height (DBH) from Terrestrial Laser Scanning (TLS) Data at Plot Level. Forests 2018, 9, 398. [CrossRef]

43. Mohan, M.; Silva, C.A.; Klauberg, C.; Jat, P.; Catts, G.; Cardil, A.; Hudak, A.T.; Dia, M. Individual Tree Detection from Unmanned Aerial Vehicle (UAV) Derived Canopy Height Model in an Open Canopy Mixed Conifer Forest. Forests 2017, 8, 340. [CrossRef]

44. Krause, S.; Sanders, T.G.M.; Mund, J.P.; Greve, K. UAV-Based Photogrammetric Tree Height Measurement for Intensive Forest Monitoring. Remote Sens. 2019, 11, 758. [CrossRef]

45. Larjavaara, M.; Muller-Landau, H.C. Measuring tree height: A quantitative comparison of two common field methods in a moist tropical forest. Methods Ecol. Evol. 2013, 4, 793-801. [CrossRef]

46. Butt, N.; Slade, E.; Thompson, J.; Malhi, Y.; Riutta, T. Quantifying the sampling error in tree census measurements by volunteers and its effect on carbon stock estimates. Ecol. Appl. 2013, 23, 936-943. [CrossRef]

47. Köppen, W. Climatologia: Con un Estudio de los Climas de la Tierra; Fundo de Cultura Econômica: México City, México, 1948; 478p.

48. Xavier, A.C.; King, C.W.; Scanlon, B.R. Daily gridded meteorological variables in Brazil (1980-2013). Int. J. Climatol. 2016, 36, 2644-2659. [CrossRef] 
49. Empresa Brasileira de Pequisa Agropecuária-EMBRAPA. Sistema Brasileiro de Classificação de Solos, 3rd ed.; Empresa Brasileira de Pequisa Agropecuária-EMBRAPA: Brasilia, Brazil, 2013; 353p.

50. QGIS. QGIS geographic information system. Open Source Geospat. Found. Proj. 2020, 1, 1-10.

51. Gonçalves, F.; Treuhaft, R.; Law, B.; Almeida, A.; Walker, W.; Baccini, A.; Dos Santos, J.R.; Graça, P. Estimating Aboveground Biomass in Tropical Forests: Field Methods and Error Analysis for the Calibration of Remote Sensing Observations. Remote Sens. 2017, 9, 47. [CrossRef]

52. Meng, J.; Li, S.; Wang, W.; Liu, Q.; Xie, S.; Ma, W. Mapping forest health using spectral and textural information extracted from spot-5 satellite images. Remote Sens. 2016, 8, 719. [CrossRef]

53. Ozdemir, I.; Karnieli, A. Predicting forest structural parameters using the image texture derived from WorldView-2 multispectral imagery in a dryland forest, Israel. Int. J. Appl. Earth Obs. Geoinf. 2011, 13, 701-710. [CrossRef]

54. Manzanera, J.A.; García-Abril, A.; Pascual, C.; Tejera, R.; Martín-Fernández, S.; Tokola, T.; Valbuena, R. Fusion of airborne LiDAR and multispectral sensors reveals synergic capabilities in forest structure characterization. GISci. Remote Sens. 2016, 53, 723-738. [CrossRef]

55. Bourdier, T.; Cordonnier, T.; Kunstler, G.; Piedallu, C.; Lagarrigues, G.; Courbaud, B. Tree Size Inequality Reduces Forest Productivity: An Analysis Combining Inventory Data for Ten European Species and a Light Competition Model. PLoS ONE 2016, 11, e0151852, [CrossRef]

56. Valbuena, R.; Packalén, P.; Martı'n-Fernández, S.; Maltamo, M. Diversity and equitability ordering profiles applied to study forest structure. For. Ecol. Manag. 2012, 276, 185-195. [CrossRef]

57. Popescu, S.C.; Wynne, R.H. Seeing the Trees in the Forest. Photogramm. Eng. Remote Sens. 2004, 70, 589-604. [CrossRef]

58. Roussel, J.R.; Auty, D.; Coops, N.C.; Tompalski, P.; Goodbody, T.R.H.; Meador, A.S.; Bourdon, J.F.; de Boissieu, F.; Achim, A. lidR: An R package for analysis of Airborne Laser Scanning (ALS) data. Remote Sens. Environ. 2020, 251, 112061. [CrossRef]

59. RC Team. R: The R Project for Statistical Computing. 2019. Available online: https://www.r-project.org/ (accessed on 30 March 2020).

60. Vastaranta, M.; Kankare, V.; Holopainen, M.; Yu, X.; Hyyppä, J.; Hyyppä, H. Combination of individual tree detection and area-based approach in imputation of forest variables using airborne laser data. ISPRS J. Photogramm. Remote Sens. 2012, 67, 73-79. [CrossRef]

61. Vastaranta, M.; Holopainen, M.; Yu, X.; Haapanen, R.; Melkas, T.; Hyyppä, J.; Hyyppä, H. Individual tree detection and area-based approach in retrieval of forest inventory characteristics from low-pulse airbone laser scanning data. Photogramm. J. Finl. 2011, $22,1-13$.

62. Gu, J.; Grybas, H.; Congalton, R.G. Individual Tree Crown Delineation from UAS Imagery Based on Region Growing and Growth Space Considerations. Remote Sens. 2020, 12, 2363. [CrossRef]

63. Wu, B.; Yu, B.; Wu, Q.; Huang, Y.; Chen, Z.; Wu, J. Individual tree crown delineation using localized contour tree method and airborne LiDAR data in coniferous forests. Int. J. Appl. Earth Obs. Geoinf. 2016, 52, 82-94. [CrossRef]

64. Khosravipour, A.; Skidmore, A.K.; Wang, T.; Isenburg, M.; Khoshelham, K. Effect of slope on treetop detection using a LiDAR Canopy Height Model. ISPRS J. Photogramm. Remote Sens. 2015, 104, 44-52. [CrossRef]

65. Keränen, J.; Maltamo, M.; Packalen, P. Effect of flying altitude, scanning angle and scanning mode on the accuracy of ALS based forest inventory. Int. J. Appl. Earth Obs. Geoinf. 2016, 52, 349-360. [CrossRef]

66. Zahawi, R.A.; Dandois, J.P.; Holl, K.D.; Nadwodny, D.; Reid, J.L.; Ellis, E.C. Using lightweight unmanned aerial vehicles to monitor tropical forest recovery. Biol. Conserv. 2015, 186, 287-295. [CrossRef]

67. Panagiotidis, D.; Abdollahnejad, A.; Surový, P.; Chiteculo, V. Determining tree height and crown diameter from high-resolution UAV imagery. Int. J. Remote Sens. 2017, 38, 2392-2410. [CrossRef]

68. Mlambo, R.; Woodhouse, I.H.; Gerard, F.; Anderson, K. Structure from Motion (SfM) Photogrammetry with Drone Data: A Low Cost Method for Monitoring Greenhouse Gas Emissions from Forests in Developing Countries. Forests 2017, 8, 68. [CrossRef]

69. Guerra-Hernández, J.; González-Ferreiro, E.; Monleón, V.J.; Faias, S.P.; Tomé, M.; Díaz-Varela, R.A. Use of Multi-Temporal UAV-Derived Imagery for Estimating Individual Tree Growth in Pinus pinea Stands. Forests 2017, 8, 300. [CrossRef]

70. Matasci, G.; Hermosilla, T.; Wulder, M.A.; White, J.C.; Coops, N.C.; Hobart, G.W.; Zald, H.S. Large-area mapping of Canadian boreal forest cover, height, biomass and other structural attributes using Landsat composites and lidar plots. Remote Sens. Environ. 2018, 209, 90-106. [CrossRef]

71. Dandois, J.P.; Ellis, E.C. Remote sensing of vegetation structure using computer vision. Remote Sens. 2010, 2, 1157-1176. [CrossRef]

72. Tinkham, W.T.; Huang, H.; Smith, A.; Shrestha, R.; Falkowski, M.J.; Hudak, A.T.; Link, T.E.; Glenn, N.F.; Marks, D.G. A comparison of two open source LiDAR surface classification algorithms. Remote Sens. 2011, 3, 638-649. [CrossRef]

73. Gillan, J.K.; Karl, J.W.; Duniway, M.; Elaksher, A. Modeling vegetation heights from high resolution stereo aerial photography: An application for broad-scale rangeland monitoring. J. Environ. Manag. 2014, 144, 226-235. [CrossRef]

74. Dietmaier, A.; McDermid, G.J.; Rahman, M.M.; Linke, J.; Ludwig, R. Comparison of LiDAR and digital aerial photogrammetry for characterizing canopy openings in the Boreal Forest of Northern Alberta. Remote Sens. 2019, 11, 1919. [CrossRef]

75. Aguilar, F.J.; Rivas, J.R.; Nemmaoui, A.; Peñalver, A.; Aguilar, M.A. UAV-Based Digital Terrain Model Generation under Leaf-Off Conditions to Support Teak Plantations Inventories in Tropical Dry Forests. A Case of the Coastal Region of Ecuador. Sensors 2019, 19, 1934. [CrossRef] 
76. Meng, R.; Wu, J.; Schwager, K.L.; Zhao, F.; Dennison, P.E.; Cook, B.D.; Brewster, K.; Green, T.M.; Serbin, S.P. Using high spatial resolution satellite imagery to map forest burn severity across spatial scales in a Pine Barrens ecosystem. Remote Sens. Environ. 2017, 191, 95-109. [CrossRef]

77. Fawcett, D.; Azlan, B.; Hill, T.C.; Kho, L.K.; Bennie, J.; Anderson, K. Unmanned aerial vehicle (UAV) derived structure-frommotion photogrammetry point clouds for oil palm (Elaeis guineensis) canopy segmentation and height estimation. Int. J. Remote Sens. 2019, 40, 7538-7560. [CrossRef]

78. Hodgson, M.E.; Bresnahan, P. Accuracy of airborne lidar-derived elevation. Photogramm. Eng. Remote Sens. 2004, 70, 331-339. [CrossRef]

79. White, J.C.; Coops, N.C.; Wulder, M.A.; Vastaranta, M.; Hilker, T.; Tompalski, P. Remote Sensing Technologies for Enhancing Forest Inventories: A Review. Can. J. Remote Sens. 2016, 42, 619-641. [CrossRef]

80. Leberl, F.; Irschara, A.; Pock, T.; Meixner, P.; Gruber, M.; Scholz, S.; Wiechert, A. Point Clouds. Photogramm. Eng. Remote Sens. 2010, 76, 1123-1134. [CrossRef]

81. Chen, S.; McDermid, G.J.; Castilla, G.; Linke, J. Measuring Vegetation Height in Linear Disturbances in the Boreal Forest with UAV Photogrammetry. Remote Sens. 2017, 9, 1257. [CrossRef]

82. Woods, M.; Pitt, D.; Penner, M.; Lim, K.; Nesbitt, D.; Etheridge, D.; Treitz, P. Operational implementation of a LiDAR inventory in Boreal Ontario. For. Chron. 2011, 87, 512-528. [CrossRef]

83. Kraus, K.; Pfeifer, N. Determination of terrain models in wooded areas with airborne laser scanner data. ISPRS J. Photogramm. Remote Sens. 1998, 53, 193-203. [CrossRef]

84. Hébert, F.; Krause, C.; Plourde, P.Y.; Achim, A.; Prégent, G.; Ménétrier, J. Effect of tree spacing on tree level volume growth, morphology, and wood properties in a 25-year-old Pinus banksiana plantation in the boreal forest of Quebec. Forests $2016,7,276$. [CrossRef]

85. Yu, X.; Hyyppä, J.; Vastaranta, M.; Holopainen, M.; Viitala, R. Predicting individual tree attributes from airborne laser point clouds based on the random forests technique. ISPRS J. Photogramm. Remote Sens. 2011, 66, 28-37. [CrossRef]

86. Jensen, J.L.R.; Mathews, A.J. Assessment of Image-Based Point Cloud Products to Generate a Bare Earth Surface and Estimate Canopy Heights in a Woodland Ecosystem. Remote Sens. 2016, 8, 50. [CrossRef]

87. Cunliffe, A.M.; Brazier, R.E.; Anderson, K. Ultra-fine grain landscape-scale quantification of dryland vegetation structure with drone-acquired structure-from-motion photogrammetry. Remote Sens. Environ. 2016, 183, 129-143. [CrossRef]

88. Díaz-Varela, R.A.; De la Rosa, R.; León, L.; Zarco-Tejada, P.J. High-Resolution Airborne UAV Imagery to Assess Olive Tree Crown Parameters Using 3D Photo Reconstruction: Application in Breeding Trials. Remote Sens. 2015, 7, 4213-4232. [CrossRef]

89. Lisein, J.; Pierrot-Deseilligny, M.; Bonnet, S.; Lejeune, P. A photogrammetric workflow for the creation of a forest canopy height model from small unmanned aerial system imagery. Forests 2013, 4, 922-944. [CrossRef]

90. Crespo-Peremarch, P.; Fournier, R.A.; Nguyen, V.T.; van Lier, O.R.; Ruiz, L.Á. A comparative assessment of the vertical distribution of forest components using full-waveform airborne, discrete airborne and discrete terrestrial laser scanning data. For. Ecol. Manag. 2020, 473, 118268. [CrossRef]

91. Vega, C.; Hamrouni, A.; El Mokhtari, S.; Morel, J.; Bock, J.; Renaud, J.P.; Bouvier, M.; Durrieu, S. PTrees: A point-based approach to forest tree extraction from lidar data. Int. J. Appl. Earth Obs. Geoinf. 2014, 33, 98-108. [CrossRef]

92. de Souza Frutuoso, L.M.; de Melo Almeida, D.; Filho, J.G.M.U.; Junior, V.C.B.; de Andrade, G.S.; do Canto, J.L. Métodos de Medição de Altura em Fragmento de Floresta Estacional Decidual. Nativa 2020, 8, 610-614. [CrossRef]

93. de Mendonça, A.R.; da Silva, J.C.; Aozai, T.S.; da Silva, E.R.; Santos, J.S.; Binoti, D.H.B.; da Silva, G.F. Estimação da Altura Total de Árvores de Ipê Felpudo Utilizando Modelos de Regressão e Redes Neurais. Rev. Bras. Biom. 2018, 36, 128-139. [CrossRef]

94. Curto, R.D.A.; Môra, R.; de Araújo, E.J.G.; da Silva, G.F. Treinamento na estimativa da altura de árvores de grande porte em floresta inequiânea. Sci. Agrar. Parana. 2018, 17, 170.

95. Hakamada, R.E.; Stape, J.L.; Lemos, C.; Emanuel, A.; Almeida, A.; Silva, L.F. Uso do inventário florestal e da uniformidade entre árvores como ferramenta de monitoramento da qualidade silvicultural em plantios clonais de eucalipto. Sci. For. 2015, 43, 27-39.

96. Ruza, M.S.; Corte, A.P.D.; Hentz, A.M.K.; Sanquetta, C.R.; Silva, C.A.; Schoeninger, E.R. Inventário de Sobrevivência de povoamento de Eucalyptus com uso de Redes Neurais Artificiais em Fotografias obtidas por VANTs. Adv. For. Sci. 2017, 4, 83-88. [CrossRef] 